\title{
ORGANIZATIONAL KNOWLEDGE ACQUISITION - STRATEGIC OBJECTIVE OF ORGANIZATION
}

\author{
Alina Luca ${ }^{1}$, Luminita Mihaela Lupu², Ionut Viorel Herghiligiu ${ }^{3}$
}

\begin{abstract}
Knowledge is now considered the most important resource of an organization, with organizational knowledge acquisition identified in literature as a process that can determine the difference between success and failure of an organization. It is considered necessary for each organization to manage the acquisition of knowledge as a central element in business continuity planning, optimizing costs, and organizational objectives. The main goal of this paper is to develop a framework for organizational knowledge acquisition. This purpose is relevant because, until now, the literature encompasses the problem of organizational knowledge acquisition through human resources, from the perspective of staff ability to learn and implement new concepts, but not from the perspective of an organizational strategy. An organization is stressed by economic and financial alliances and by clients and suppliers. These constrain managers from identifying new solutions to problems. This study is relevant for business because it analyzes an important direction for the development of strategies in the context of market globalization and for academic research because there has been little research previously in this direction.
\end{abstract}

JEL Classification Numbers: M21, M10, DOI: http://dx.doi.org/10.12955/cbup.v4.753

Keywords: knowledge management, organizational knowledge acquisition, organizational strategy.

\section{Introduction}

Contemporary economic situations have led to the shift in considering an organization as a resources based view (RBV) approach to that of a knowledge based view (KBV) approach. This change is because knowledge is now considered the main "raw material" that adds value to the organization and makes it competitive in the dynamic and competing environment. In this context, at the organizational level, the correct management of knowledge in the knowledge management (KM) domain, underpins organization success. Organizational knowledge acquisition (OKA) is primary to KM processes. In literature, OKA has been mainly considered through the human resources available to the organization, namely in terms of their ability to learn and implement new concepts, and not through the OKA as an organizational strategy. In this context, the main objective of this paper is to develop a conceptual framework for the OKA, by developing a concrete model of OKA.

The purpose of this paper is to clarify and to improve the OKA process. Furthermore, the objectives of the paper are to present and provide a general description of KM and identify the KM components; OKA presentation and clarification; and developing a model of OKA. The paper is based on a bibliographic research, followed by consultation of a panel of five specialists acting in academic and business fields. The paper is structured as follows: a synthetic analysis of the literature regarding KM and OKA (research objectives 1 and 2); development of the OKA model (research objective 3); and the conclusions.

\section{Knowledge Management (KM) - Presentation and General Description}

Knowledge management is the process of managing intellectual capital, available in any organization, to achieve the organization's objectives. There is no universally accepted definition of KM, but scholars agree that KM can be divided into several processes: acquisition, transfer, creation, sharing, and reusing knowledge (Souad, 2015).

\footnotetext{
1 Alina Luca, Department of Engineering and Management, "Gheorghe Asachi” Technical University of Iasi, Romania, alisluca@hotmail.com

${ }^{2}$ Luminita Mihaela Lupu, Department of Engineering and Management, "Gheorghe Asachi" Technical University of Iasi, Romania, iherghelegiu@tex.tuiasi.ro

${ }^{3}$ Ionut Viorel Herghiligiu, Lupu, Department of Engineering and Management, "Gheorghe Asachi" Technical University of Iasi, Romania, luminitalupu2011@gmail.com
} 
Knowledge acquisition (KA) is the first of the KM processes, and was approached as a concept in the literature in the mid-1930s, when Bertol Brecht considered, for the first time, that knowledge can be traded.

In the organizational KM literature, the different theories and models identified, in total, conclude that the acquisition of organizational knowledge is part of organizational learning, along with dissemination of knowledge and its use to achieve the objectives of the organization (Argote, 1999; Dibella \& Nevis, 1998; Morgan, 1997; Huber, 1991; Helleloid \& Simonin, 1994; Kim, 1993; Morgan \& Ramirez, 1983). Gharajedaghi and Ackoff (1984) cited by Niu (2010) showed that where knowledge is not used in creating value for the company, it becomes data or information that are eminently descriptive and instructive in answering "how to" questions. Niu (2010) noted that scholars use different terminologies for OKA, as shown in Table 1.

Table 1: Terms used by scholars for organizational knowledge acquisition

\begin{tabular}{|ll|}
\hline Author (year) & Terms \\
\hline Nonaka and Takeuchi (1995) & Knowledge creation \\
Huber (1991) & Knowledge acquisition \\
Cohen and Levinthal (1990) & Absorption capacity \\
March (1991) & Knowledge exploration and exploitation \\
\hline Source: Niu (2010) & \\
\hline
\end{tabular}

\section{Literature Models Regarding Organizational Knowledge Acquisition (OKA)}

The literature presents several models of OKA that show differences between knowledge acquisition at the individual level and OKA.

The model proposed by Motta, Rajan, and Eisenstadt (2015) identified KA as having the following steps: acquiring knowledge, data analysis, and the conceptualization of the domain.

Huber (1991) proposed a model of OKA that consists of the following stages: acquisition of knowledge, distribution of information, interpretation, and storing knowledge in organizational memory.

Cohen and Levinthal (1990) proposed the following model: the recognition of the value of the new information, assimilation of new knowledge, and the commercial use (exploitation) of the acquired knowledge.

Grant (1996) proposed a model that consists of three main steps:

1. Acquiring knowledge through two operations

a. the acquisition of knowledge from organizational members, or by employed staff that hold the knowledge needed by the organization, but not encompassed; and

b. knowledge creation;

2. Assimilating of the new knowledge; and

3. Application of the new knowledge.

Holsapple and Joshi (2004) proposed the following model: identification of the knowledge, capturing of the knowledge identified in the external environment, captured knowledge, and transfer of the organized knowledge.

Zahra and George (2002) divided the OKA process, called absorption capacity in potential capacity, which includes the acquisition and assimilation of knowledge and achieved capacity, involving knowledge transformation and exploitation.

Nieminen (2007) proposed the following model of OKA: identification, transmission, processing, storage, and reinterpreting knowledge.

Ghauri and Park (2012) proposed the model: understanding, assimilation of the new knowledge, processing, and exploitation of the new knowledge.

Acquisition of knowledge can be structural, based on activities that are planned, organized, and systematized (Kohli, Jaworski, B., \& Kumar, 1993; Loon Hoe \& McShane, 2010), or informal, based 
on the spontaneous and voluntary information collection activities (Akgun, Lynn, \& Byrne, 2003; Dibella \& Nevis, 1998; Nonaka \& Takeuchi, 1995; Swap, Leonard, Shields, \& Abrams, 2001). Knowledge creation is part of the KA process, consisting of converting acquired knowledge from outside the organization into new knowledge within the organization (Sun, 2010; Loon Hoe \& McShane, 2010).

\section{Organizational Knowledge Acquisition (OKA) Model}

Organizational knowledge acquisition, as previously stated, is part of knowledge management. From the analysis of the models presented in literature in the previous section, we present those we have considered representative.

Table 2 shows the phases involved in each of the representative cases, which are listed by author. The phase of identifying the necessary knowledge (knowledge findings) for the organization was identified in about $25 \%$ of the models; the phase for obtaining this knowledge (knowledge acquire) in about $75 \%$ of models; the stage of assimilation of the acquired knowledge in 60\%; and that of valuing the acquired knowledge in about $65 \%$ of the analyzed models (Table 2).

Table 2: Phases of organizational knowledge acquisition (OKA) in models by authors

\begin{tabular}{l}
\hline Author \\
Phases \\
\begin{tabular}{|l|c|c|c|c|c|c|c|c|}
\hline Knowledge findings & {$[1]$} & & & & & $\mathrm{x}$ & $\mathrm{x}$ & \\
\hline Knowledge acquire & $\mathrm{x}$ & $\mathrm{x}$ & & $\mathrm{x}$ & $\mathrm{x}$ & $\mathrm{x}$ & & $\mathrm{x}$ \\
\hline Knowledge analyze & $\mathrm{x}$ & & & & & & & \\
\hline Conceptualization & $\mathrm{x}$ & & & & & & & $\mathrm{x}$ \\
\hline Distribution & & $\mathrm{x}$ & & & & $\mathrm{x}$ & $\mathrm{x}$ & \\
\hline $\begin{array}{l}\text { Interpretation/ } \\
\text { Transformation }\end{array}$ & & $\mathrm{x}$ & & $\mathrm{x}$ & & & $\mathrm{x}$ & $\mathrm{x}$ \\
\hline Organizational memory & & $\mathrm{x}$ & $\mathrm{x}$ & & $\mathrm{x}$ & $\mathrm{x}$ & $\mathrm{x}$ & \\
\hline Value recognition & & & $\mathrm{x}$ & & & & & \\
\hline Commercial use & & & $\mathrm{x}$ & $\mathrm{x}$ & & & & \\
\hline Application & & & & & $\mathrm{x}$ & & $\mathrm{x}$ & $\mathrm{x}$ \\
\hline
\end{tabular}
\end{tabular}

Table legend:

[1] Motta, Rajan, and Eisenstadt, 2015; [2] Huber, 1991; [3] Cohen and Levinthal, 1990; [4]

Zahra and George, 2002; [5] Grant, 1996; [6] Holsapple and Joshi, 2004; [7] Nieminen, 2007;

[8] Ghauri and Park, 2012

Source: Author

In models presented in the literature, the presented stages can be grouped into three major categories, namely:

1. Knowledge pre-acquisition phase, which covers strategic findings of the organizational knowledge needs;

2. Knowledge acquisition phase, which covers the acquirer of the knowledge needed by the organization; and

3. Knowledge post-acquisition phase, which covers assimilation and exploitation of the acquired knowledge.

Starting with the theoretical models mentioned above and the specialist's opinion (from the panel), we developed a proposal for an organizational knowledge acquisition model (Figure 1), which involves three stages:

In this model, Stage-I comprises the knowledge pre-acquisition phase, which covers the strategic phase, concrete identification of organization's outside knowledge that the organization needs and which it does not own. Zack (2002), Reus and Lamont (2009), and McIver (2011) identified the 
importance of the knowledge that organizations need but do not own, and the selection available from the multitude of existing knowledge on the market. A clear and coherent strategy provides the necessary framework for searching new knowledge and information (Adams et al., 2006; Zahra \& George, 2002). The strategic objectives of any organization should be clear and transparent (Lane, Koka, \& Pathak, 2006; Zahra \& George, 2002; Zheng, Yang, T., Pardo, T. \& Jiang, 2009). It must rely on information from the external organizational environment (Chen \& Chang, 2008) and be related to the customer's values (Hansen, Nohria, N., \& Tireney, 1999).

Stage-II is the knowledge acquisition phase, which covers the acquirer of the knowledge from external sources, through:

1. Know-how acquisition; and

2. Employment of experts who have the necessary knowledge for organization.

The existence of prior knowledge can be grouped into knowledge about the technology and that about the product, and at the individual level this provides the ability to identify and acquire new knowledge to produce radical innovations within the organization (Lichtenthaler \& Lichtenthaler, 2009; Sun, 2010).

Figure 1: Model of organizational knowledge acquisition

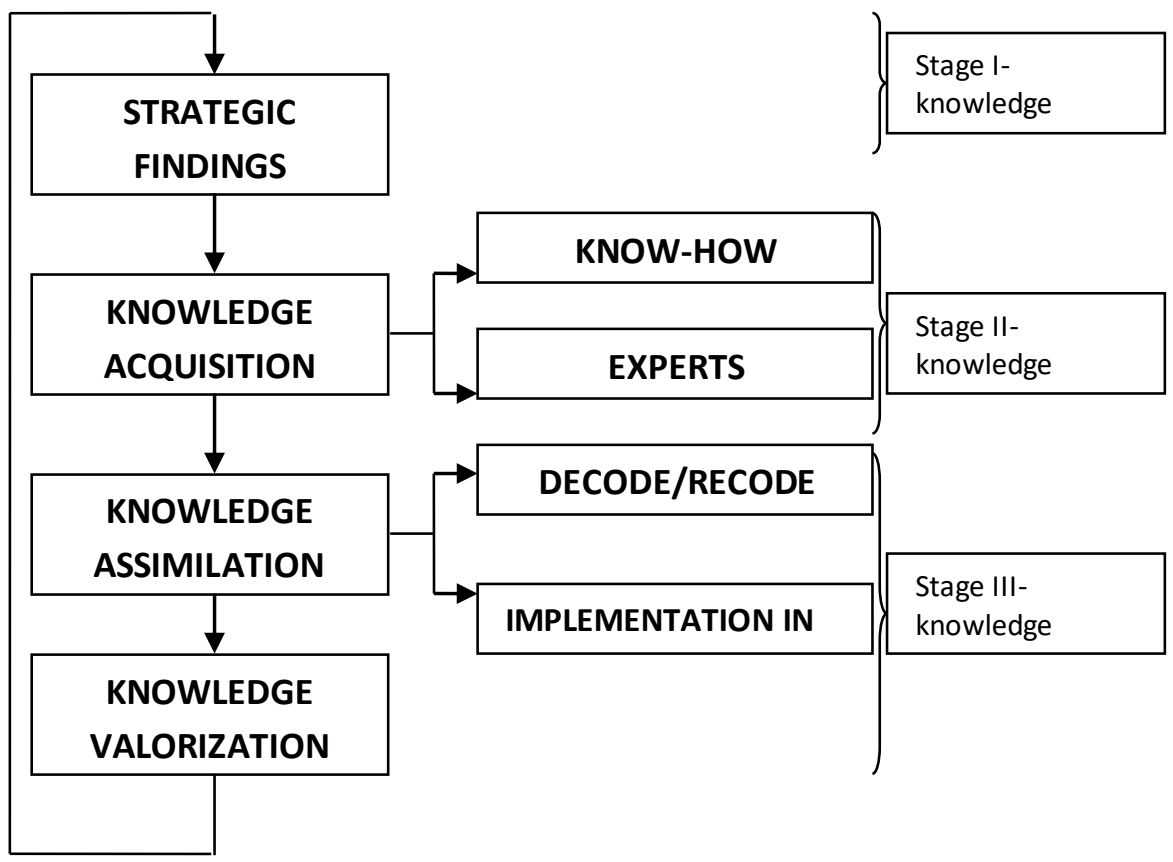

Source: Author

Stage-III is the knowledge post-acquisition phase, which covers:

1. Assimilation of the acquired knowledge through

a. the decoding of the acquired knowledge and its transposition in easily understandable forms by organizational members; and

b. implementation of the knowledge in the organization's procedures.

An organization that establishes routine in ensuring transparencies in a strategic direction motivates people to share their knowledge and encourages them to identify more efficient ways to use and exploit existing knowledge bases. A lack of transparency prevents the use and sharing of knowledge. Lack of transparency is seen as an obstacle of innovation within the organization, especially when endeavoring to restructure the products and services (Sun, 2010). 
2. Valorization of the acquired knowledge, with respect to obtaining profit following the implementation of newly-acquired knowledge in organizational routines; Lubit (2001) cited by Nieminen (2007) observed that the acquisition of new knowledge is not enough, the competitive advantage of the company being the result of the value and sustainability of its knowledge, and of its future skills of developing and finding new possibilities to apply the value that knowledge will achieve in the organization.

Organizational knowledge acquisition is a cyclical process, which resumes under the influence of market requirements that any organization (political or economic) needs to implement to survive.

This model is based on the literature and represents a strictly theoretical proposal which will be developed with extensive and ongoing empirical research.

The model is original because it emphasizes $\mathrm{KA}$ as a primary process of $\mathrm{KM}$ and an activity that contributes to achieving the organizational objectives in dynamic conditions of the market. In this context, KA becomes a strategic objective of the organization.

Development of this model is important from several perspectives:

- From an academic perspective, the model offers the possibility for further studies regarding KA as a dynamic process within the organization;

- From a collegiate perspective, OKA represents the basis for innovation, and accordingly, may be included in university curricula;

- From the perspective of policy makers, OKA can be supported by funding programs that promote lifelong learning, allow practitioners access to scientific resources and databases, and avails meetings between academia and business; and

- Practitioners within the organization will need to allocate resources for KA as it is an essential process in the organization's progress and a primary process in KM.

\section{Conclusions}

The literature shows that organizations with a high degree of knowledge acquisition are more competitive, act proactively in the economic environment, and exploit opportunities, unlike organizations with a limited involvement in knowledge management, which tend to be reactive (Cohen \& Levinthal, 1990). The proposed model is original because it integrates all phases of knowledge acquisition, starting with the strategic findings of knowledge, acquisition by hiring specialists or buying know-how, assimilation of knowledge acquired, to the step of valorization of the acquired knowledge as input for subsequent knowledge management. The model is simple, easy to run, and manageable by practitioners; and its steps are simple to follow in knowledge management.

\section{References}

Adams, W. K., Perkins, K. K., Podolefsky, N. S., Dubson, M., Finkelstein, N. D., Wieman, C. E. (2006). New instrument for measuring student beliefs about physics and learning physics: The Colorado Learning Attitudes about Science Survey, Physical review special topics - physics education research, 2, 94.

Akgun, A. E., Lynn, G. S., \& Byrne J. C. (2003). Organizational learning: a socio-cognitive framework. Human Relations, 56(7), 839-868

Argote, L. (1999). Organizational Learning: Creating, Retaining, and Transferring Knowledge. Retrieved March 1, 2016 from http://www.jstor.org/stable/2667112?seq=1\#page_scan_tab_contents

Chen, S. W., \& Chang, H. (2008). The impact of online store environment cues on purchase intention: Trust and perceived risk as a mediator, Online Information Review, 32 (6), 45.

Cohen, W. M., \& Levinthal, D. A. (1990). Absorptive Capacity: A New Perspective on Learning and Innovation, Administrative Science Quarterly, Special Issue: Technology, Organizations, and Innovation, 35(1), 128-152.

DiBella, A. J., \& Nevis, E. C. (1998). How organizations learn: an integrated strategy for building learning capability, 84. Gharajedaghi, J., \& Ackoff, L. R. (1984). Mechanisms, organisms and social systems, Strategic Management Journal 5.3: 289-300.

Ghauri, P. N., \& Park, I. B. (2012). The Impact of Turbulent Events on Knowledge Acquisition, Comparison of Cross-border Acquisitions Formed Before and After the Crisis, Manag. Int. Rev., 52, 293-315.

Grant, R. M. (1996). Toward A Knowledge-Based Theory of the Firm, Strategic Management Journal, 17(Winter Special Issue), 109-122.

Hansen, M. T., Nohria, N., \& Tireney, T. (1999). What's Your Strategy for Managing Knowledge? Harvard Business Review, 106-116. 
Helleloid, D., \& Simonin, B. (1994). “Organizational learning and a firm's core competence" in Competence based competition, Gary Hamel, Aimé Heene (Eds), John Wiley \& Sons, Chichester, 213-239.

Holsapple, C. W., \& Joshi, K. D. (2004). A Knowledge Management Ontology, Handbook on Knowledge Management, 89120.

Huber, G. P. (1991). Organizational Learning: The Contributing Processes and the Literatures, Organization Science, Organizational Learning: Papers in Honor of (and by) James G. March., 2(1), 88-115.

Kim, D. H. (1993). The Link between Individual and Organizational Learning, Sloan Management Review, 37-50

Kohli, A., Jaworski, B., \& Kumar, A. (1993). Markor: A Measure of Market Orientation, Journal of Marketing Research, 30(4), 467-477.

Lane, P. J., Koka, B. R., \& Pathak, S. (2006). The reification of absorptive capacity: A critical review and rejuvenation of the construct. Academy of Management Review, 4, 833- 863.

Lichtenthaler, U., \& Lichtenthaler, E. (2009). A Capability-Based Framework for Open Innovation: Complementing Absorptive Capacity, Journal of Management Studies, 46(8), 1315-1338.

Loon Hoe, S., \& McShane, S. (2010). Structural and informal knowledge acquisition and dissemination in organizational learning, The Learning Organization, 17(4), 364-386.

Lubit, R. (2001). Tacit Knowledge and Knowledge Management: The Keys to Sustainable Competitive Advantage, Organizational Dynamics, 29(4), 164-178.

March, A. S. (1991), Exploration and exploitation in organizational learning, Organization Science, Vol. 2 No. 1, pp. $71-87$. McIver, D. (2011). Knowledge-in Practice: Exploring the Influence of Knowledge Management Processes on Performance. Morgan, G. (1997). Images of Organization, Thousand Oaks, CA: Sage Publications, 1997.

Morgan, G., \& Ramirez, R. (1983). Action Learning: A Holographic Metaphor for Guiding Social Change. Human Relations, 37(1), 1-27.

Motta, E., Rajan, T. \& Eisenstadt, M. (2015). Knowledge Acquisition as a Process of Model Refinement.

Nieminen, H. (2007). Developing competences through inter-organizational knowledge acquisition, Esa Print Tampere, Tampere.

Nonaka, I., \& Takeuchi, H. (1995). The knowledge-creating company, New York: Oxford University Press.

Niu, K. H. (2010). Knowledge management practices and organizational adaptation; Evidences from high technology companies in China, Journal of Strategy and Management, 3(4), 325-343.

Reus, T., \& Lamont, B. (2009). The double-edged sword of cultural distance in international acquisitions, Journal of International Business Studies, 25, 1-19.

Souad, D. (2015). Knowledge Management and Intellectual Capital in an Enterprise Information System, European Conference on Knowledge Management, 213-221.

Sun, P. (2010). Five Critical Knowledge Management Organizational Themes, Journal of Knowledge Management, 14(4) 507-523.

Swap, W., Leonard, D., Shields, M. \& Abrams, L. (2001). Using Mentoring and Storytelling to Transfer Knowledge in the Workplace, Journal of Management Information Systems, 19(1), 95-114.

Zack, M. H. (2002). Developing a knowledge strategy, The strategic management of intellectual capital and organizational knowledge, Oxford University Press, 255-276.

Zahra, S. A. \& George, G. (2002). Absorptive Capacity: A Review, Reconceptualization, and Extension, The Academy of Management Review, 27(2) 185-203.

Zheng, L. Yang, T., Pardo, T. \& Jiang, Y. (2009). Understanding the 'boundary' in Cross-boundary Information Sharing, Proceedings of the 42th Hawaii International Conference on System Sciences, 1-10. 